\title{
Online Balint Group Work Versus Pharmacotherapy in Treatment of Coronavirus Anxiety in Healthcare Workers in Iran: A Pilot Randomized Controlled Trial
}

najmeh shahini

Golestan University of Medical Sciences and Health Services

shakiba gholamzad

Iran University of Medical Sciences: Tehran University of Medical Sciences

zanireh salimi ( $\nabla$ psychiatric.disorders@yahoo.com )

Mashhad University of Medical Sciences

Mansoureh Kiani Dehkordi

University of Social Welfare and Rehabilitation Science

Saeedeh Hajebi Khaniki

Mashhad University of Medical Sciences

Reza Rahimzadeh Oskoei

Mashhad University of Medical Sciences

Hossein Mohaddes Ardabili

Mashhad University of Medical Sciences

Research

Keywords: Online Balint group work, Pharmacotherapy, Anxiety, Resilience, COVID-19

Posted Date: September 3rd, 2021

DOl: https://doi.org/10.21203/rs.3.rs-770855/v1

License: (c) (i) This work is licensed under a Creative Commons Attribution 4.0 International License.

Read Full License 


\section{Abstract}

Background: An increase in symptoms of anxiety is already being reported in relation to the COVID-19 pandemic.

Objectives: We aimed to compare the effectiveness of Balint group work with pharmacotherapy in coronavirus related anxiety among healthcare workers (HCWs) in Iran.

Methods: In This pilot clinical trial, after passing a phone screening procedure by a psychiatrist, subjects were quasi-randomly assigned to Balint (8 sixty-minute online sessions) or pharmacotherapy (Sertraline) groups. Both groups were asked to fill two questionnaires, including the Corona Disease Anxiety Scale (CDAS) and Connor-Davidson resilience scale (CD-RISC), at the beginning and the end of the 4-week intervention period.

Results: A total of $45 \mathrm{HCW}$ enrolled in this study. The results showed a significant difference between the post-test and pre-test scores of both groups in the total scores of anxiety and its subcomponents $(p \leq 0.001)$. There was no significant difference between the effectiveness of the two interventions on anxiety $(p=0.52)$. Both interventions had a significant effect on the subjects' resilience and its subscales $(p \leq 0.05)$ except for positive acceptance change. The spiritual influences domain had a significantly higher increase in the pharmacotherapy group $(P=0.031)$.

Conclusions: We showed Balint group work maybe can better to pharmacotherapy with Sertraline in management of COVID-19 related anxiety and boosting resilience in healthcare workers.

\section{Introduction}

The coronavirus disease (COVID-19), as a highly contagious infection with a long incubation period, emerged in Wuhan at the end of 2019. It has gained intense attention worldwide and caused huge threats to individuals' mental health (1). Recently, the world health organization (WHO) projected the need for action on mental health and considered the front-line healthcare workers (HCWs) to be at greater risk of psychological problems. During such pandemics, HCWs in the front line have to deal with long work hours, greater risk of infection transmission, social isolation, and getting homesick, all of which can potentially give rise to serious psychiatric problems $(1,2)$.

The COVID-19 pandemic is a rapidly evolving situation and psychological status of HCWs may be altered in time. Few studies have been done on the probable strategies that could be used to address the psychological needs of front-line HCWs during this pandemic (3).

One of the interventions for reducing anxiety and increasing resilience in the HCWs is Balint group intervention. Balint group is a group of trained and peer therapists and caregivers discussing the difficulties and issues in their relationship with patients in a reflective, insightful, and practical way (4). 
The aim of Balint group is changing the uncertainty, confusion, and difficulty of perception, understanding, and meaning in the relationship between the caregiver and patient leading to a stronger therapeutic alliance (5). It also empowers physicians to take the initiative in their profession when there is

uncertainty or no clear answer (6) and it helps them to explore their interpersonal abilities and limitations, perceive and strengthen the blind spots in dealing with patients (7).

In one study, the effectiveness of Balint group was evaluated in nurses of intensive care units (ICUs). The results showed a significant effect of Balint group work on reducing burnout and improving the work quality of nurses (8).

To date, more than 1.4 million Iranian COVID-19 cases have been confirmed (9). The number of morbidities, including psychological complications, are higher, especially in vulnerable groups. However, few studies addressed the treatment of anxiety and increasing resilience in the medical staff as one the most at-risk groups. Various pharmacological and non-pharmacological interventions have been effective in increasing resilience and decreasing anxiety caused by $\operatorname{COVID-19}(10,11)$. Different studies on the effect of the aforementioned treatments have reported contradictory results.

To the best of our knowledge, there is no study comparing the effectiveness of Balint group with pharmacotherapy in the HCWs. Therefore, we aimed to compare the effectiveness of Balint group and pharmacotherapy with selective serotonin reuptake inhibitors (SSRIs) in coronavirus related anxiety and resilience among HCWs.

\section{Materials And Methods}

\section{Study Design}

This pilot quasi-randomized controlled study performed over four weeks in Gorgan, Iran from March 2020 to May 2020. After completing the written informed consent, patients were quasi-randomly assigned into parallel intervention groups, namely Balint group work or pharmacotherapy. We performed an alternate allocation method according to the order of enrollment. The first participant to fulfill the inclusion criteria was assigned to Balint group work, the second participant was assigned to the pharmacotherapy group, and the allocation continued in this alternating way. The pilot trial protocol was registered at irct.ir (Registration code: IRCT20200411047023N1, registration date: 26/01/2021, available at: https://www.irct.ir/trial/53441).

\section{Participants}

A total of 60 individuals were assessed for eligibility criteria, from which 15 cases were excluded. The remaining participants were divided into two groups, including 17 participants in pharmacotherapy group and 28 participants in the Balint group (Fig. 1). We included cases with 18-59 years of age with illness anxiety who had been diagnosed by two psychiatrists, according to the Diagnostic and Statistical Manual of Mental Disorders, fifth edition (DSM-5). Participants were excluded from the study if they had 
psychiatric disorders other than illness anxiety, were treated with psychiatric drugs or were pregnant. A blinded psychiatric coordinator screened the HCWs for eligibility criteria via a phone call interview.

\section{Intervention}

Participants in the Balint group attended eight sessions in four weeks. Participants in the pharmacotherapy group received 4-week of oral Sertraline tablets (starting with $50 \mathrm{mg} /$ day and increased if needed according to the patient's symptoms and tolerance). Due to the high rates of coronavirus transmission, it was not possible to hold face-to-face groups, and Balint groups were held virtually via Skype video calls with nine members, one leader and one assistant leader for 60 minutes per session, two times a week. An additional 15 minutes could be added. To collect data at the beginning and end of the 4week intervention period, individuals in each group answered demographic and research questionnaires. All participants were evaluated at the beginning and the end of the study (pre-and post-test).

\section{Sample size:}

To achieve the appropriate number of research samples, G-power version 3.1.9.2 (17) software was used, considering the significance level of 0.05 and beta of 0.8 and the effect size of 0.5 according to a related study (12). The appropriate sample size was 16 people and considering the possible drop-out rate, 20 participants were considered as the appropriate number of cases in each group.

\section{Data collection}

\section{The study questionnaire, which included Corona Disease Anxiety Scale and Connor-Davidson resilience scale, was prepared online in the Google Forms platform (available at https}

//forms.gle/QWmXdBEFKs2FXEy27) and distributed in social networks. In this format, a brief statement about the purpose of the research and the principal investigator was included to introduce the survey. Participants' demographic data (such as age, sex, educational status, and marital status) was also collected.

\section{Ethical considerations}

The study design was approved by Golestan University of Medical Sciences (ethical code: IR.GOUMS.REC.1399.023). All participants were informed that participation is voluntary and reassured that their records would remain confidential.

\section{Research tools}

\section{Corona Disease Anxiety Scale (CDAS)}

This instrument has been developed and validated in the Iranian population to measure anxiety caused by coronavirus outbreak. This instrument consists of 18 items in two subscales of psychological (items 1 to 9 ) and physical (items 10 to 18) symptoms. This tool is rated on a 4-point Likert scale (never $=0$, 
sometimes $=1$, most of the time $=2$, and always $=3$ ), so respondents' scores range from 0 to 54 . Higher scores indicate higher levels of anxiety. The reliability of this tool was obtained using Cronbach's alpha method for the first factor $(a=0.879)$ and the second factor $(a=0 / 861)$ and the whole questionnaire as $(a=0.919)(13)$.

\section{CD-RISC resilience scale (Connor-Davidson resilience scale)}

This tool is measured by Connor and Davidson and consists of 25 items on a five-choice Likert scale (completely incorrect $=0$, rarely true $=1$, sometimes true $=2$, often true $=3$, and always true $=4$ ), and its overall score ranges from $0-100$. The score of each subject is equal to the sum of the scores of all 25 questions. Higher scores represent higher resilience in the respondent and vice versa. The cut-off point is set on 50, which means scores higher than 50 will indicate resilience, and the higher the score, the higher the resilience, and vice versa (14).

The results of factor analysis indicate that this test has five factors: the perception of personal competence, trust in individual instincts, tolerance of negative emotions, positive acceptance of change and safe relationships, control, and spiritual effects (14). Cronbach's alpha coefficient for the total resilience score was 0.93 in the Iranian version of the questionnaire (15).

\section{Statistical analysis:}

The data were analyzed using SPSS software (Version 16, Chicago, IL, USA), and the significance level was set at $\mathrm{P}<0.05$. Data were shown as mean \pm SD or frequency (\%). Homogeneity of demographic variables was checked by Chi-square test, Fisher's exact test where applicable or t-test. The normality of continuous variables was checked using the Shapiro-Wilk test. Since variables were not normally distributed, comparison between the two groups was made using Wilcoxon signed-ranked test. The difference between quantitative variables after the intervention was studied using the analysis of covariance (ANCOVA) while considering baseline and those confounding variables as confounders. The correlation between CDAS and its subscale differences (after-before) and CD-RISC and its subscale differences (after-before) were evaluated using Spearman's correlation coefficient.

\section{Results}

In this study, 45 eligible subjects were randomized in Balint $(n=28)$ and pharmacotherapy $(n=17)$ groups (Fig. 1). Five cases dropped due to non-adherence, and 40 could finish the study intervention after four weeks. No harm, unintended or critical side effects were observed during the intervention period. The female-to-male ratio was 21/4 and 12/3 in Balint and pharmacotherapy groups, respectively. The mean age of the individuals was $34.0 \pm 5.5$ years in the Balint group and $31.8 \pm 3.9$ years in the pharmacotherapy group $(P=0.18)$. Furthermore, most participants were married and had children. The percentage of individuals with Ph.D. degrees was $68.0 \%$ in the Balint group, while most people in the pharmacotherapy had a bachelor's or master's degree. Moreover, all the people in the pharmacotherapy 
group were in contact with suspicious patients with COVID-19, but there were some people in the Balint group who had no history of close contact with COVID-19 patients in their workplace (Table 1.)

Table 1

Comparison of demographic variables between Balint and pharmacotherapy groups.

\begin{tabular}{|c|c|c|c|}
\hline & $\begin{array}{l}\text { Balint } \\
(n=25)\end{array}$ & $\begin{array}{l}\text { Pharmacotherapy } \\
(n=15)\end{array}$ & p-value* \\
\hline \multicolumn{4}{|l|}{ Sex } \\
\hline Male & $4(16.0 \%)$ & $3(20.0 \%)$ & \multirow[t]{2}{*}{$>0.99$} \\
\hline Female & $21(84.0 \%)$ & $12(80.0 \%)$ & \\
\hline Age (years) & $34.0 \pm 5.5$ & $31.8 \pm 3.9$ & 0.184 \\
\hline \multicolumn{4}{|l|}{ Marital status } \\
\hline Single & $9(36.0 \%)$ & $3(20.0 \%)$ & \multirow[t]{2}{*}{0.477} \\
\hline Married & $16(64.0 \%)$ & $12(80.0 \%)$ & \\
\hline \multicolumn{4}{|l|}{ Education level } \\
\hline MD & $5(20.0 \%)$ & $6(40.0 \%)$ & \multirow[t]{3}{*}{$<0.001$} \\
\hline BSC or MSC & $3(12.0 \%)$ & $9(60.0 \%)$ & \\
\hline $\mathrm{PhD}$ & $17(68.0 \%)$ & 0 & \\
\hline \multicolumn{3}{|l|}{ Having children } & \multirow[t]{3}{*}{0.622} \\
\hline Yes & $13(52.0 \%)$ & $9(60.0 \%)$ & \\
\hline No & $12(48.0 \%)$ & $6(40.0 \%)$ & \\
\hline \multicolumn{3}{|l|}{ Contact with COVID-19 patients in workplace } & \multirow[t]{4}{*}{0.002} \\
\hline Close contact with COVID-19 patients & $11(44.0 \%)$ & 0 & \\
\hline Contact with suspicious COVID-19 patients & $11(44.0 \%)$ & $15(100.0 \%)$ & \\
\hline No contact with COVID-19 patients & $3(12.0 \%)$ & 0 & \\
\hline \multicolumn{4}{|l|}{ Data were presented as Mean $\pm S D$, frequency (\%). } \\
\hline * Based on Fisher's exact test, Chi-square te & test. & & \\
\hline
\end{tabular}

The mean level of CDAS score in the Balint group was $12.3 \pm 12.7$ comparing to $12.7 \pm 8.4$ in pharmacotherapy group, which was not significantly different $(P \geq 0.52)$. Since the workplace, level of education, and total score of CDAS was significantly different between the two groups, ANCOVA was done. As shown in Table 2, after adjusting for confounders, the score of CDAS was not significantly different between the two groups $(P=0.53)$. The mean decline of psychological and physical symptoms 
was higher in the pharmacotherapy group and Balint group, respectively. Nonetheless, none of the mentioned differences were statistically significant $P>0.05$ ). Also, a significant improvement was seen in CDAS scores and its subscales in both groups after the intervention $(P<0.01$, Table 2.).

Table 2

Comparison of Corona Disease Anxiety Scale and its subscales' scores between Balint and pharmacotherapy groups.

\begin{tabular}{|c|c|c|c|c|}
\hline \multirow[t]{2}{*}{ Variable } & \multirow[t]{2}{*}{ Timepoint } & \multicolumn{2}{|l|}{ Group } & \multirow{2}{*}{$\begin{array}{l}\text { Adjusted } \\
\text { p-value }\end{array}$} \\
\hline & & $\begin{array}{l}\text { Balint } \\
(n=25)\end{array}$ & $\begin{array}{l}\text { Pharmacotherapy } \\
(\mathrm{n}=15)\end{array}$ & \\
\hline \multirow[t]{4}{*}{$\begin{array}{l}\text { Score in the psychological symptoms } \\
\text { subscale of CDAS }\end{array}$} & Before & $\begin{array}{l}13.7 \pm \\
5.9\end{array}$ & $19.7 \pm 4.7$ & \multirow[t]{4}{*}{$0.888^{đ}$} \\
\hline & After & $\begin{array}{l}7.2 \pm \\
3.6\end{array}$ & $12.3 \pm 5.7$ & \\
\hline & Difference & $\begin{array}{l}-6.5 \pm \\
6.0\end{array}$ & $-7.4 \pm 5.5$ & \\
\hline & p-value & $\begin{array}{l}< \\
0.001^{\dagger}\end{array}$ & $0.002^{\dagger}$ & \\
\hline \multirow[t]{4}{*}{$\begin{array}{l}\text { Score in the physical symptoms } \\
\text { subscale of CDAS }\end{array}$} & Before & $\begin{array}{l}9.0 \pm \\
7.5\end{array}$ & $15.8 \pm 5.3$ & \multirow[t]{4}{*}{$0.164^{đ}$} \\
\hline & After & $\begin{array}{l}3.2 \pm \\
2.6\end{array}$ & $10.5 \pm 6.1$ & \\
\hline & Difference & $\begin{array}{l}-5.8 \pm \\
7.2\end{array}$ & $-5.3 \pm 4.1$ & \\
\hline & p-value & $0.001^{\dagger}$ & $0.002^{\dagger}$ & \\
\hline \multirow[t]{4}{*}{ Total CDAS score } & Before & $\begin{array}{l}22.7 \pm \\
12.6\end{array}$ & $35.5 \pm 9.5$ & \multirow[t]{4}{*}{$0.527^{đ}$} \\
\hline & After & $\begin{array}{l}10.4 \pm \\
5.3\end{array}$ & $22.9 \pm 11.3$ & \\
\hline & Difference & $\begin{array}{l}-12.3 \pm \\
12.7\end{array}$ & $-12.7 \pm 8.4$ & \\
\hline & $p$-value & $\begin{array}{l}< \\
0.001^{\dagger}\end{array}$ & $0.001^{\dagger}$ & \\
\hline \multicolumn{5}{|l|}{ Data presented as Mean \pm SD. } \\
\hline \multicolumn{5}{|l|}{${ }^{\dagger}$ Based on Wilcoxon signed rank test. } \\
\hline
\end{tabular}


Based on CDAS scores, before the intervention, $20.0 \%$ and $36.0 \%$ of individuals in the Balint group had moderate and severe corona disease anxiety, respectively, both of which reduced to $4.0 \%$ after the intervention. Besides, in the pharmacotherapy group, the frequency of mild anxiety increased from $0.0-$ $20.0 \%$, and the frequency of severe corona-related anxiety decreased from $73.3-20.0 \%$ after the intervention (Fig. 2).

There was a significant improvement in CD-RISC subscale scores including personal competence, trust in one's instincts, tolerance, and spiritual influences after the intervention in both groups, however, positive acceptance of change subscale scores had a significant decrease $(P<0.05)$. Comparison of total scores of CD-RISC and its domains after the intervention while adjusting for mentioned covariates indicated no significant difference between the two groups except for the spiritual influences domain, which had a significantly higher increase in the pharmacotherapy group $(P=0.03$, Table 3 .). 
Table 3

Comparison of Connor-Davidson Resilience Scale between Balint and pharmacotherapy groups.

\begin{tabular}{|c|c|c|c|c|}
\hline \multirow[t]{2}{*}{ Variable } & \multirow[t]{2}{*}{ Timepoint } & \multicolumn{2}{|l|}{ Group } & \multirow{2}{*}{$\begin{array}{l}\text { Adjustec } \\
\text { p-value }\end{array}$} \\
\hline & & $\begin{array}{l}\text { Balint } \\
(n=25)\end{array}$ & $\begin{array}{l}\text { Pharmacotherapy } \\
(\mathrm{n}=15)\end{array}$ & \\
\hline \multirow[t]{4}{*}{ Personal competence } & Before & $19.4 \pm 11.1$ & $16.3 \pm 2.5$ & \multirow[t]{4}{*}{$0.696^{₫}$} \\
\hline & After & $26.9 \pm 4.4$ & $25.9 \pm 5.5$ & \\
\hline & Difference & $7.6 \pm 9.7$ & $9.7 \pm 5.0$ & \\
\hline & $\mathrm{p}$-value & $0.003^{\dagger}$ & $0.001^{\dagger}$ & \\
\hline \multirow[t]{4}{*}{ Trust in one's instincts } & Before & $16.1 \pm 8.7$ & $13.9 \pm 2.5$ & \multirow[t]{4}{*}{$0.364^{\ddagger}$} \\
\hline & After & $22.5 \pm 3.5$ & $22.2 \pm 5.1$ & \\
\hline & Difference & $6.4 \pm 8.4$ & $8.3 \pm 4.5$ & \\
\hline & $\mathrm{p}$-value & $0.001^{\dagger}$ & $0.001^{\dagger}$ & \\
\hline \multirow[t]{4}{*}{ Positive acceptance of change } & Before & $13.6 \pm 7.4$ & $10.0 \pm 1.8$ & \multirow{4}{*}{$0.111^{đ}$} \\
\hline & After & $3.7 \pm 2.0$ & $7.1 \pm 4.3$ & \\
\hline & Difference & $-9.9 \pm 7.1$ & $-2.9 \pm 4.4$ & \\
\hline & $\mathrm{p}$-value & $<0.001^{\dagger}$ & $0.018^{\dagger}$ & \\
\hline \multirow[t]{4}{*}{ Control } & Before & $7.9 \pm 4.1$ & $6.2 \pm 0.9$ & \multirow[t]{4}{*}{$0.790^{\ddagger}$} \\
\hline & After & $10.0 \pm 1.9$ & $9.5 \pm 2.1$ & \\
\hline & Difference & $2.2 \pm 3.5$ & $3.3 \pm 1.9$ & \\
\hline & p-value & $0.007^{\dagger}$ & $0.001^{\dagger}$ & \\
\hline \multirow[t]{4}{*}{ Spiritual influences } & Before & $4.2 \pm 2.9$ & $3.9 \pm 0.9$ & \multirow[t]{4}{*}{ 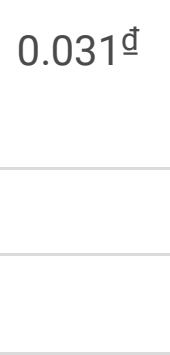 } \\
\hline & After & $5.4 \pm 1.7$ & $6.3 \pm 1.3$ & \\
\hline & Difference & $1.2 \pm 2.8$ & $2.4 \pm 1.3$ & \\
\hline & $\mathrm{p}$-value & $0.059^{\dagger}$ & $0.001^{\dagger}$ & \\
\hline Total CD-RISC score & Before & $61.2 \pm 33.3$ & $50.3 \pm 7.7$ & $0.527^{đ}$ \\
\hline
\end{tabular}

Data presented as Mean \pm SD.

${ }^{\dagger}$ Based on Wilcoxon signed rank test.

${ }^{\ddagger}$ Based on ANCOVA adjusted for measurements before intervention, education level and workplace. 


\begin{tabular}{|llll|}
\hline & After & $82.6 \pm 11.9$ & $80.0 \pm 16.4$ \\
\cline { 2 - 3 } & Difference & $21.4 \pm 29.0$ & $29.7 \pm 14.5$ \\
\cline { 2 - 4 } & p-value & $0.004^{\dagger}$ & $0.001^{\dagger}$ \\
\hline Data presented as Mean \pm SD. & & \\
\hline${ }^{\dagger}$ Based on Wilcoxon signed rank test. & \\
\hline đBased on ANCOVA adjusted for measurements before intervention, education level and workplace. \\
\hline
\end{tabular}

There was a significant negative correlation between CDAS and CD-RISC difference scores (after-before) in Balint groups. We also investigated the correlation between subscales of two studied questionnaires. As shown in Table 4, there was a significant correlation between all subscales of CDAS and CD-RISC in the Balint group. In contrast to the Balint group, the correlation between positive acceptance of change and CDAS, psychological symptoms scores were positive and significant (Table 4). 
Table 4

Correlation of Corona Disease Anxiety and Connor-Davidson Resilience Scale in Balint and pharmacotherapy groups.

\begin{tabular}{|c|c|c|c|c|c|c|c|}
\hline & & \multicolumn{2}{|l|}{ CDAS } & \multicolumn{2}{|c|}{$\begin{array}{l}\text { psychological } \\
\text { symptoms }\end{array}$} & \multicolumn{2}{|c|}{$\begin{array}{l}\text { physical } \\
\text { symptom }\end{array}$} \\
\hline & & $r$ & $\begin{array}{l}\text { P- } \\
\text { VALUE* }\end{array}$ & $r$ & $\begin{array}{l}\text { P- } \\
\text { VALUE* }\end{array}$ & $r$ & $\begin{array}{l}\text { P- } \\
\text { VALUE* }\end{array}$ \\
\hline \multirow{6}{*}{$\begin{array}{l}\text { Balint } \\
\text { group }\end{array}$} & CD-RISC & -0.742 & $<0.001$ & -0.791 & $<0.001$ & -0.728 & $<0.001$ \\
\hline & $\begin{array}{l}\text { Personal } \\
\text { competence }\end{array}$ & -0.772 & $<0.001$ & -0.841 & $<0.001$ & -0.731 & $<0.001$ \\
\hline & $\begin{array}{l}\text { Trust in one's } \\
\text { instincts }\end{array}$ & -0.737 & $<0.001$ & -0.798 & $<0.001$ & -0.747 & $<0.001$ \\
\hline & $\begin{array}{l}\text { Positive } \\
\text { acceptance of } \\
\text { change }\end{array}$ & -0.751 & $<0.001$ & -0.825 & $<0.001$ & -0.694 & $<0.001$ \\
\hline & control & -0.781 & $<0.001$ & -0.782 & $<0.001$ & -0.790 & $<0.001$ \\
\hline & $\begin{array}{l}\text { Spiritual } \\
\text { influences }\end{array}$ & -0.787 & $<0.001$ & -0.726 & $<0.001$ & -0.806 & $<0.001$ \\
\hline \multirow{6}{*}{$\begin{array}{l}\text { Pharmacotherapy } \\
\text { group }\end{array}$} & CD-RISC & -0.336 & 0.221 & -0.448 & 0.094 & -0.087 & 0.757 \\
\hline & $\begin{array}{l}\text { Personal } \\
\text { competence }\end{array}$ & -0.334 & 0.223 & -0.456 & 0.088 & -0.105 & 0.711 \\
\hline & $\begin{array}{l}\text { Trust in one's } \\
\text { instincts }\end{array}$ & -0.459 & 0.085 & -0.477 & 0.072 & -0.258 & 0.353 \\
\hline & $\begin{array}{l}\text { Positive } \\
\text { acceptance of } \\
\text { change }\end{array}$ & 0.649 & 0.009 & 0.654 & 0.008 & 0.395 & 0.146 \\
\hline & control & -0.435 & 0.105 & -0.502 & 0.056 & -0.269 & 0.333 \\
\hline & $\begin{array}{l}\text { Spiritual } \\
\text { influences }\end{array}$ & -0.011 & 0.968 & -0.246 & 0.376 & 0.255 & 0.358 \\
\hline
\end{tabular}

\section{Discussion}

Anxiety is now a common psychological complication among HCWs during the COVID-19 pandemic (16). However, few studies addressed the coping strategies and treatments to mitigate this complication. We aimed to compare the effectiveness of Balint group therapy with pharmacotherapy in decreasing coronavirus anxiety and increasing resilience in health care workers dealing with COVID-19. 
During a critical situation like the COVID-19 pandemic, one of the major problems of HCWs is increased anxiety. Anxiety is the result of suppressing emotions and feelings which were not expressed (17). Moreover, job stress occurs when job requirements are not matched with worker's authorities and abilities (18). Several factors are important in creating and permanence of anxiety including traumatic experiences of health care providers in hospitals, especially those who deal with patients. They usually suppress negative emotions and do not express their experiences, blame themselves for failure and tragic events, and have a high expectation of their abilities (18).

Our study showed that there is no significant difference between the effectiveness of Balint group therapy and pharmacotherapy in decreasing anxiety and increasing resilience. Regarding the effectiveness of Balint group therapy on anxiety and resilience, we found a notable decrease in anxiety and increase in resilience among HCWs. This result is consistent with the result of previous studies $(19,20)$.

Furthermore, the ability to empathize is in having the right relationship with the patient, to follow the treatment, and to help in the prediction of clinical consequences (12). Balint groups are designed to assist health professionals and medical students in developing their empathy skills and reducing interpersonal problems (21). So, Balint group can result in the reduction of anxiety in health care providers.

Resilience is the capacity to respond to stress in a healthy way to achieve goals at minimum physical and psychological costs. Persons with this ability facing challenges without bouncing back, so they become stronger than ever. Resilience is key to enhance the quality of care and sustainability of workers in healthcare. In the literature review, we noticed that Balint group improves the wellbeing and empathy of healthcare providers through narrative interactions and appreciative inquiry-based dialogues and increases resilience, and helps them to apply more proper methods to deal with stress (22). In another study, self-awareness and self-monitoring were introduced as effective methods in increasing resilience in healthcare providers (23).

Therefore, these results confirm that Balint group increases resilience in healthcare workers by 1 . Dealing with different aspects of the patient-therapist relationship (24), 2. creating opportunities to express experiences, feelings, and self-reflections to other members (25), 3. informing the individual of their power and abilities and helping them understand and analyze (25), 4. Enhancing their empathy and interaction with the patient (12), 5. Helping caregivers express their suppressed negative emotion, 6 . Helping them to develop their mutual understanding, 7. Helping them to change their misperceptions about unpleasant experiences and not to feel alone, 9 . Reducing the rate of anxiety in health caregivers, 10 . Helping them to increase their capacity responding anxiety through reviewing their past experiences and challenges (26, 27).

The other intervention that was used in this study was pharmacotherapy with a significant effect on the reduction of anxiety and increasing resilience. These results are consistent with results of other studies $(28,29)$. 
SSRIs are the first line pharmacological treatment for anxiety disorders (28). The serotonin system plays an important role in the neural processing of anxiety and the involvement of serotonin reuptake receptors in the dysfunctionality of anxiety has a wide research background (29). Serotonin reuptake receptors increase neurotransmitters which result in the reduction of anxiety in people. In a study on the effect of serotonin on the resilience of civilians suffering from post-traumatic stress disorder, the results showed that serotonin works as a protective factor against stress and increases the resistance to stress and helps people be more flexible to anxious situations and results in an increase resilience (30).

Although drug interventions have essential and rapid effects, they have many side effects with a reduction in therapeutic effects after finishing their use. On the contrary, psychological interventions have no side effect and can keep their therapeutic effect, however, they are too time-consuming (31).

\section{Declarations}

\section{Ethics approval and consent to participate:}

The study was conducted in accordance with the Declaration of Helsinki and approved by the ethics committee at Golestan University of Medical Sciences (IR.GOUMS.REC.1399.023). All participants were informed that participation is voluntary and reassured that responses would remain confidential. Informed written consent was also obtained from all participants filling in the questionnaires. Participants may withdraw from the trial at any point without any penalty and will not receive compensation for taking part.

In the study personal information about participants collected during the consent/data collection processes are stored securely

Consent for publication: not applicable.

\section{Availability of data and materials:}

The data for the current study will not be shared publicly as participants were informed at the time of providing consent that only researchers involved in the project would have access to the information they provided. Researchers and scientific institutions can access the anonymous results by sending their request to the corresponding author.

\section{Competing interests:}

The authors declare that they have no competing interests.

\section{Funding:}

The study was funded by Golestan University of Medical Sciences, Gogan, Iran. (Investigators including two psychiatrists who voluntarily do the screening and follow-up visits and prescriptions, also Balint group leader, co-leader, and other investigators did not charge participants or funding organization for 
their services. Routine executive expenses were supported by the Golestan University of Medical Sciences, Gorgan, Iran)

\section{Authors' contributions}

Najmeh Shahini: data collection, writing the article, and final approval of the article; Shakiba Gholamzad and Mansoureh Kiani Dehkordi: study concept and design, and Administrative support; Zanireh Salimi: writing the article, data collection, and literature review, Reza Rahimzadeh Oskoei: critical revision of the article, provision of the materials, patients, and resources; Saeedeh Hajebi Khaniki: statistical analysis; and Hossein Mohaddes Ardabili: literature review, critical revision of the article, drafting the manuscript. All the mentioned authors critically reviewed the manuscript for key intellectual content and approved the final version of the manuscript.

\section{Acknowledgements:}

The authors would like to thank Golestan Research Center of Psychiatry (GRCP) for voluntary participation and cooperation in the study. We also appreciate kind collaboration of Mostafa Mansouri in reviewing related literature.

Author details

\section{References}

1. Kang L, Li Y, Hu S, Chen M, Yang C, Yang BX, et al. The mental health of medical workers in Wuhan, China dealing with the 2019 novel coronavirus. The Lancet Psychiatry. 2020;7(3):e14.

2. Zhu Z, Xu S, Wang H, Liu Z, Wu J, Li G, et al. COVID-19 in Wuhan: Immediate Psychological Impact on 5062 Health Workers. medRxiv. 2020.

3. Ahern NR, Norris AE. Examining factors that increase and decrease stress in adolescent community college students. J Pediatr Nurs. 2011;26(6):530-40.

4. Van Roy K, Vanheule S, Inslegers R. Research on Balint groups: A literature review. Patient Educ Couns. 2015;98(6):685-94.

5. Cataldo KP, Peeden K, Geesey ME, Dickerson L. Association between Balint training and physician empathy and work satisfaction. Fam Med. 2005;37(5):328-31.

6. Shorer Y, Rabin S, Maoz B, Nadav M, Shiber A. Empowering doctors in Balint groups. Balint Journal. 2007;8(04):122-5.

7. Stojanovic-Tasic M, Latas M, Milosevic N, Pribakovic JA, Ljusic D, Sapic R, et al. Is Balint training associated with the reduced burnout among primary health care doctors? Libyan Journal of Medicine. 2018;13(1). 
8. Huang $\mathrm{H}$, Zhang $\mathrm{H}$, Xie Y, Wang S-B, Cui H, Li L, et al. Effect of Balint group training on burnout and quality of work life among intensive care nurses: A randomized controlled trial. Neurology Psychiatry Brain Research. 2020;35:16-21.

9. WHO Weekly Epidemiological Updates on Coronavirus disease (COVID-19). 2021 [Available from: https://www.who.int/emergencies/diseases/novel-coronavirus-2019/situation-reports.

10. Khawam E, Khouli H, Pozuelo L. Treating acute anxiety in patients with COVID-19. Cleveland Clinic journal of medicine. 2020.

11. Fullana MA, Hidalgo-Mazzei D, Vieta E, Radua J. Coping behaviors associated with decreased anxiety and depressive symptoms during the COVID-19 pandemic and lockdown. J Affect Disord. 2020;275:80-1.

12. Ha JF, Longnecker N. Doctor-patient communication: a review. Ochsner Journal. 2010;10(1):38-43.

13. Alipour A, Ghadami A, Alipour Z, Abdollahzadeh H. Preliminary validation of the Corona Disease Anxiety Scale (CDAS) in the Iranian sample. Quarterly Journal of Health Psychology. 2020;8(32):163-75.

14. Connor KM, Davidson JR. Development of a new resilience scale: the Connor-Davidson Resilience Scale (CD-RISC). Depress Anxiety. 2003;18(2):76-82.

15. Jowkar B. The mediating role of resilience in the relationship between general and emotional intelligence and life satisfaction. 2007.

16. Pappa S, Ntella V, Giannakas T, Giannakoulis VG, Papoutsi E, Katsaounou P. Prevalence of depression, anxiety, and insomnia among healthcare workers during the COVID-19 pandemic: A systematic review and meta-analysis. Brain, behavior, and immunity. 2020.

17. Silverman WK, van Schalkwyk GI. What Is Anxiety? Pediatric Anxiety Disorders: Elsevier; 2019. p. 716.

18. Chang EM, Daly JW, Hancock KM, Bidewell J, Johnson A, Lambert VA, et al. The relationships among workplace stressors, coping methods, demographic characteristics, and health in Australian nurses. Journal of professional nursing. 2006;22(1):30-8.

19. Howard R, Kirkley C, Baylis N. Personal resilience in psychiatrists: systematic review. BJPsych bulletin. 2019;43(5):209-15.

20. Van Roy K, Vanheule S, Inslegers R. Research on Balint groups: a literature review. Patient Educ Couns. 2015;98(6):685-94.

21. Turner AL, Malm RL. A preliminary investigation of Balint and non-Balint behavioral medicine training. FAMILY MEDICINE-KANSAS CITY-. 2004;36(2):114-7.

22. Epstein RM, Krasner MS. Physician resilience: what it means, why it matters, and how to promote it. Acad Med. 2013;88(3):301-3.

23. Zwack J, Schweitzer J. If every fifth physician is affected by burnout, what about the other four? Resilience strategies of experienced physicians. Acad Med. 2013;88(3):382-9. 
24. Chew BW, Tiew LH, Creedy DK. Acute care nurses' perceptions of spirituality and spiritual care: an exploratory study in Singapore. Journal of clinical nursing. 2016;25(17-18):2520-7.

25. Olds J, Malone J. The implementation and evaluation of a trial balint group for clinical medical students. Journal of the Balint Society. 2016;44:31-9.

26. Khalaila R, Cohen M. Emotional suppression, caregiving burden, mastery, coping strategies and mental health in spousal caregivers. Aging Ment Health. 2016;20(9):908-17.

27. Harmsen JA, Bernsen R, Meeuwesen L, Pinto D, Bruijnzeels M. Assessment of mutual understanding of physician patient encounters: Development and validation of a mutual understanding scale (MUS) in a multicultural general practice setting. Patient Educ Couns. 2005;59(2):171-81.

28. Jakubovski E, Johnson JA, Nasir M, Müller-Vahl K, Bloch MH. Systematic review and meta-analysis: Dose-response curve of SSRIs and SNRIs in anxiety disorders. Depress Anxiety. 2019;36(3):198212.

29. Grieb Z, Ragan C. The effects of perinatal SSRI exposure on anxious behavior and neurobiology in rodent and human offspring. Eur Neuropsychopharmacol. 2019;29(11):1169-84.

30. Landi G, Pakenham KI, Boccolini G, Grandi S, Tossani E. Health anxiety and mental health outcome during COVID-19 lockdown in Italy: the mediating and moderating roles of psychological flexibility. Frontiers in psychology. 2020;11:2195.

31. Chen T-R, Huang H-C, Hsu J-H, Ouyang W-C, Lin K-C. Pharmacological and psychological interventions for generalized anxiety disorder in adults: A network meta-analysis. J Psychiatr Res. 2019;118:73-83.

\section{Figures}

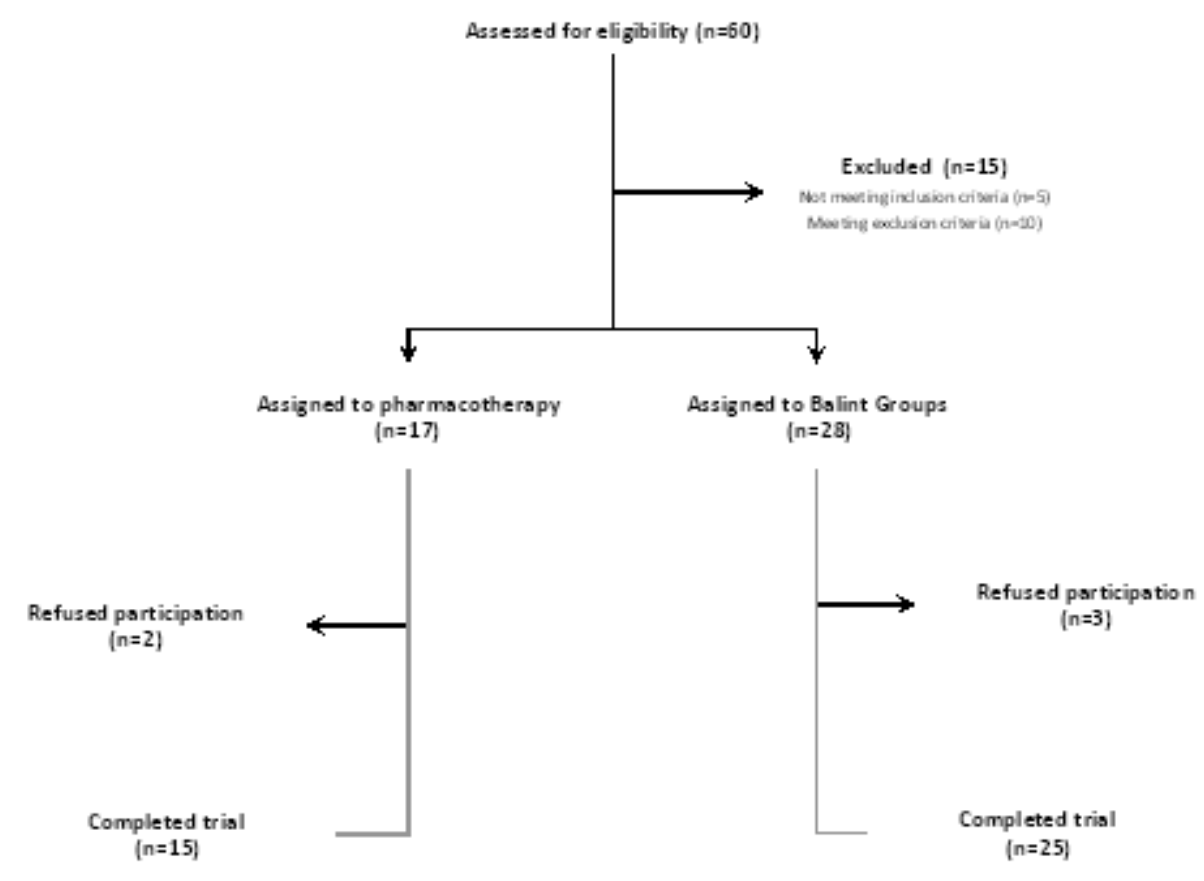


Figure 1

Quasi-experimental diagram showing the disposition of all subjects screened for the study. Corona Disease Anxiety Scale

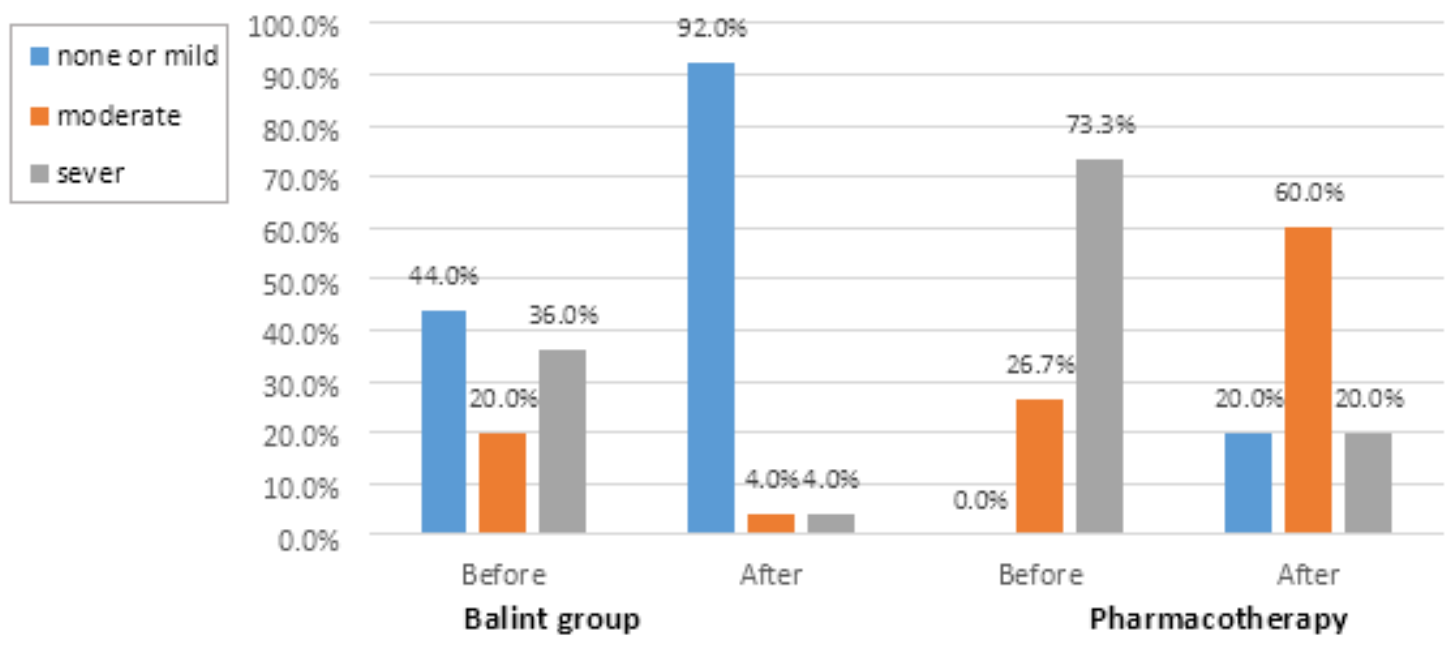

Figure 2

Frequency of Corona Disease Anxiety in Balint and pharmacotherapy groups.

\section{Supplementary Files}

This is a list of supplementary files associated with this preprint. Click to download.

- CONSORT2010ChecklistHMA.doc 